University of Wollongong

Research Online

Faculty of Law, Humanities and the Arts Papers (Archive)

Faculty of Arts, Social Sciences \& Humanities

$1-1-2012$

A case study of globalized knowledge flows: Guanxi in social science and management theory

Xiaoying Qi

University of Western Sydney, xiaoying@uow.edu.au

Follow this and additional works at: https://ro.uow.edu.au/lhapapers

Part of the Arts and Humanities Commons, and the Law Commons

Research Online is the open access institutional repository for the University of Wollongong. For further information contact the UOW Library: research-pubs@uow.edu.au 


\title{
A case study of globalized knowledge flows: Guanxi in social science and management theory
}

\begin{abstract}
This article examines globalized knowledge flows through a case study of the treatment of the Chinese concept of guanxi in social and management science journals. Three forms of concept- theory relations are postulated which effectively correspond with different patterns of knowledge flow. The treatment of this concept in 214 refereed journal articles published from 1999 to 2009 indicates that the concept guanxi, which possesses capacity for theoretical development, is predominantly treated merely as an object of study rather than the basis of theoretical elaboration. A continuing dominant pattern of knowledge flows from the metropole to the periphery is thus indicated. The mechanisms of continuing asymmetrical knowledge flow are discussed, including language used, site of publication, channel of transmission and method as factors generating this outcome.
\end{abstract}

\section{Keywords}

case, science, theory, social, management, guanxi, flows, knowledge, globalized, study

\section{Disciplines}

Arts and Humanities | Law

\section{Publication Details}

Qi, X. (2012). A case study of globalized knowledge flows: Guanxi in social science and management theory. International Sociology, 27 (6), 707-723. 


\title{
A Case Study of Globalized Knowledge Flows: Guanxi in Social Science and Management Theory
}

\begin{abstract}
Xiaoying Qi

\section{Introduction}

Globalization is the process through which economic goods and resources, people, cultural practices, techniques and knowledge circulate more or less freely across the restrictions of national barriers. The flow and mobility of knowledge, and its organizational, technical and cultural apparatuses, are implicated in the movements of goods and services, people, ideas, and cultural products that are central to globalization. The discernible patterns, structures or shapes of globalized knowledge flows are not symmetrical between the different regions of the globalized world but asymmetrical, reflecting associated inequalities of resources and capacities and also imbalances of political and economic power. The asymmetries of globalized knowledge flows tend to parallel the inequalities associated with the practices of Western dominance. A question arises of whether knowledge flows of this type are sustainable in a world in which globalization has effectively encouraged participants from non-Western cultures to challenge the asymmetric patterns of Western hegemony.

In consideration of the present structure and possible challenge to globalized knowledge flows this paper provides a case study of approaches to and treatments of the Chinese concept of guanxi in social science and management literatures over the past decade. There has been an interest on the part of academic writers to explore and apply guanxi in discussion of Chinese business as well as social and cultural practices. These sources show that guanxi is an important concept for understanding Chinese relationships, including those of in business and management.
\end{abstract}

The paper reports a review of 214 journal articles concerning the concept guanxi published during an eleven-year period from January 1999 to December 2009. The role of institutions, publishers and publishing practices are considered below, and also the treatment of guanxi in terms of the language in which it is discussed, the method applied in apprehending it, and in its relationship with the theory to which it is applied. Consideration of the discussion of guanxi in articles appearing in a large number of social science and management journals published in America and Europe is used to examine the degree to which the theories used in these studies have been modified by their apprehension of this concept; that is, whether the direction of 'knowledge flow' has been influenced by such contact. The importance of the academic discussion of guanxi to the present paper is that it permits an examination of the direction and nature of knowledge flows, and indicates not only whether it continues to reflect Western dominance but also, if it does, what are its likely future prospects.

\section{Globalization and Knowledge Flows}

Global processes today involve almost every aspect of political, social, economic and cultural life. Through globalization there is enhanced access to information and knowledge even though the direction of knowledge flow remains predominantly from the metropole to the periphery. Because of their economic and political power, the dominant Western countries are also centres of knowledge production and circulation. The theories, concepts and methodologies used by social and cultural researchers from Angola to Zanzibar are to a large degree generated in North America and Western Europe from where they are disseminated to the rest of the world. In a review of the rebuilding of sociology in the People's Republic of 
China from the 1980s Dai (1993: 94) reports that 'most of Chinese sociological research is currently still purely applied research, while the theory and methodology are mostly adopted from the West'. This situation remains more or less unchanged today (Wu, 2009).

The idea of a 'knowledge flow' requires some explanation. The concept of knowledge indicates an awareness of something acquired through experience of it, and therefore refers to a state of mind concerning a fact, a thing or an event. While 'knowledge' thus refers to a form of understanding it can also indicate a recorded body of information about a subject. The notion of knowledge in this latter sense is not confined to a state of mind but refers to a record of statements. Such statements possess a form that includes concepts and theories, and also the methods adapted to generate the knowledge that has conceptual and theoretical form. Knowledge in these terms may be materially manifest in the form of books and journals and is almost always culturally embedded in both the manner of its expression and communication and also in terms of the practices and identities of the groups associated with it. Indeed, knowledge 'as a cognitive practice [is] ... a medium of cultural production', as Delanty (1999: 184) puts it. Knowledge is also embedded in technologies of various sorts. Knowledge therefore can refer not only to a state of mind but also to more tangible things that may be associated with particular social or economic groups, geographic regions, or cultural practices. Knowledge in this sense can be subject to possession, appropriation and movement.

Knowledge flow, as indicated in the previous paragraph, refers to the movement of particular concepts, theories and methods between distinct social and economic groups, geographic regions and cultural settings. Knowledge flow may be manifest in the movement of technologies and in cultural exchanges. It always involves the availability of concepts, theories and methods to those outside of the group, area or culture in which it is originally produced. Textbooks constitute a particularly important vehicle of knowledge flow as they serve as conduits in the diffusion of theories and concepts which derive from the social experiences or institutional assumptions of knowledge producers for dissemination to neophytes (Fleck 1981: 112; Kuhn 1970: 19-20, 141-3, 192-206). This pedagogic stratification is functional when a 'shared education, language experience and culture is assumed' (Kuhn 1970: 193), but likely to be dysfunctional when these assumptions cease to hold. In the hard sciences "not only the equipment and most of the books used in [African] laboratories and libraries are imported from the North, but moreover, the best laboratories, and the best and biggest libraries are located in the North' (Hountondji 2002: 32).

The concept of 'knowledge flow', as described above, refers to clusters of ideas, practices, modes of thinking, customs, agendas and routines which facilitate and expedite effects, outcomes, results and problem-solving in other places and at other times (Moran and Keane, 2010: 2). There is a view that under globalization knowledge flows are multidirectional and can thus be part of what Appadurai (1990) characterizes as global cultural flows. Appadurai (1990: 296) writes that the "new global cultural economy has to be understood as a complex, overlapping, disjunctive order, which cannot any longer be understood in terms of existing centre-periphery models (even those that might account for multiple centres and peripheries)'. Lash and Urry (1994: 4) similarly indicate that the prevailing conception of the world is increasingly directed to de-centeredness. While not discounting a multi-centricity of flows, criss-crossing flows and counter-flows, Hannerz (1997: 6), more in line with the discussion in this paper, argues that the representations of 'asymmetries of flow during the last century or so seem ... undeniable, involving for example the spread of some of those fundamental skills and central institutional forms which we refer to collectively as modernity; say, western-origin types of basic and higher education, administrative practices, or biomedicine (even when these are adopted in forms which are not exact copies of the original)'. 
Knowledge flow, while implicated in the movements of goods and services, people, ideas, and cultural products that are central to globalization, also has a relatively independent existence in a number of ways. These include the development of both education and publishing as international industries, and the development of knowledge transfer and knowledge management as specialist activities.

The type of knowledge of interest in this paper is knowledge about society, including the concepts and theories such knowledge consists of. According to Connell (2007) this form of knowledge flows from the metropole, through the conduits of American, British and Western European institutions and fields, to the rest of the world. Social theory necessarily derives from or reflects social and political experiences. And yet in a globalized world much of the social and political experience that may be productive of social theory is at odds with the conceptualizations internal to the sociological knowledge of the metropole contained in books and articles published in London, New York or Paris, say, but made available in other parts of the world to the exclusion of local products. Bourdieu (1999: 221) expresses this concern regarding this prospect by pointing out that texts produced in the metropole and globally distributed 'do not bring with them the field of production of which they are a product, and the fact that the recipients, who are themselves in a different field of production, re-interpret the texts in accordance with the structure of the field of reception, are facts that generate some formidable misunderstandings'. Thus in a globalized world Western theory and concepts become increasingly vulnerable to critique, challenge, modification and incorporation in extraneous cultural spaces.

It is important to acknowledge that the uneven knowledge flows referred to here are not the result of globalization per se, although globalization may exacerbate existing inequalities for reasons we shall consider. Holton (2005: 1) notes that while many commentators have seen globalization as a major cause of inequality, others argue that it is 'a way of addressing these social ills'. In recognising that globalization opens access to and facilitates international movement of students and scholars, Altbach (2004: 7) argues that 'in many respects, existing inequalities are only reinforced and new barriers erected' by globalization. He says that 'multinational corporations, media conglomerates, and even a few leading universities, can be seen as the new neo-colonists - seeking to dominate not for ideological or political reasons but rather for commercial gain' (Altbach, 2004: 9). Other researchers caution that 'there is the dangerous possibility for globalization to be synonymous with Americanisation and a weak form of internationalisation of research, which would simply mean the inclusion of more people in the conversations of researchers without challenging their western, metropolitan forms' (Lingard, 2006: 289). These positions are consistent with the idea expressed in this paper that apparent decentredness of knowledge flow requires critical examination.

Universities with international impact, which are the major sources of primary knowledge production, are predominantly situated in the metropole of economic and political power concentrations. The structure and content of research knowledge, as Boden and Epstein (2006: 230) write, are shaped 'by universities, with their globalised standards, recruitment criteria and the shaping of journal editorial policies'. The major research universities, such as Cambridge and Oxford in Britain and Harvard and Chicago in the United States, exercise a tremendous influence 'on knowledge concentrations and flows' (Marginson, 2008: 311), through which a global configuration of the direction of research is generated. As Marginson (2008: 305) puts it, these universities 'concentrate knowledge power to themselves by housing most leading researchers ... and [the] global power of these institutions rest on the subordination of other institutions and nations'.

The prevailing pattern is for universities in Africa and Asia, as well as in Australia and New Zealand, to adopt British and American models of training and instruction and also the 
forms and practices of research that are developed and popularized in them (Altbach, 2004; Beerkens, 2010: 375; Crossman and Devisch, 2002: 97; Nordtveit, 2010). There is a certain inevitability in the process. The established universities in the economically dominant countries are able to attract resources - economic, technological and intellectual - which sustain their sovereign status. These are the destinations which attract international students, researchers and scholars, who are effectively the human conduits of Western theory to their home region on graduation and through their standing at home as the 'brightest and the best'. Students graduating from these universities enjoy the benefits of their institutional prestige and international networks and therefore have opportunities for appointment and promotion which at the same time reinforces the dominant positions of these universities. The international influence of prestigious books, journals and textbooks, as knowledge carriers and transmitters, is more or less dominated by universities and similar institutions in the metropole, which is a further contributor to the hegemonic position of Western theories.

In globalized knowledge production and circulation Western or metropolitan forms tend to dominate research and dissemination. This is not simplistic 'Americanization' and in fact it is always possible that non-Western cultural forms may have representation, but typically after passing through the lens of American, say, preferences and institutions. French philosophy and Zen Buddhist teachings, for instance, enter global circuits after they have been translated into English and published by American university or commercial presses. Shambhala Publications, whose head office is in Boston, is the single-most significant source of publications on Buddhism and other Eastern religions in the world today. Indeed, globalization has not entailed the disappearance of non-American or non-Western knowledge or culture. It is possible to agree with Turner and Khondker (2010: 32), that 'local culture does not surrender itself un-problematically to forces from outside; rather it absorbs as it valorizes its own distinctiveness', while accepting that the inclusion of local culture in globalized circuits is the result of forces outside of such cultures and these outside forces select them for their own reasons and purposes.

While globalization enhances opportunities for access to knowledge and cultural exchange, and arguably increases such opportunities, it remains true that the exchange in question continues to be unbalanced in ways we shall consider below. Globalization has enhanced possibilities for the diffusion of knowledge from the East or the South or the periphery to the West as well as from the West to the rest. A spread of awareness of Chinese, Indian and Japanese ideas and texts in the United States and in Europe is at a much higher level today than it was fifty years ago. As one minor indication of this shift, the bookselling website Amazon.com, accessed 24 April 2011, listed 98 different English-language publications of the Chinese classic Daodejing (Tao Te Ching), 37 of them published since 2009. The ready and increasing availability of translations of the classics of Buddhism, Confucianism, Sufism and other non-Western texts testifies to a flow of knowledge from the East or South. But such a flow continues to be a very minor stream.

The flows of knowledge resources among nations, as McMahon (1992) notes, are interconnected with global political, economic and cultural relationships. Due to the political and economic dominance of the metropole the institutions associated with it inevitably tend to dominate knowledge production and circulation, and while they may not do so completely their intellectual agendas are unavoidably stamped on any extraneous knowledge production. In like manner Castells (1996: 412) refers to the cosmopolitan global elites' dominance of the 'cultural world of flows' and Bauman (1998) notes the dichotomic tendency in which there is globalization for some and localization for others. In similar terms, Hannerz (2008: 114) points to the way in which the 'distribution of culture within the world is affected by a structure of asymmetrical, centre/periphery, relationships'. Perhaps the strongest statement comes from Miike (2006: 5), who holds that even in the post-colonial and post-modern age, 
Euro-centrism as a universalist ideology can still be seen to pervasively and extensively permeate all fields of study and spheres of life.

\section{Guanxi and Concept-Theory Relations}

The concept of guanxi is extensively used in China and the Chinese-language areas of Taiwan, Hong Kong and Singapore as well as in overseas Chinese communities in Southeast Asia. It refers to long-term mutually reinforcing and reciprocal interactions between individuals constitutive of networks of relationships. Many commentators claim that it is characteristically Chinese in nature. Instrumentally purposive activities in particular draw upon guanxi networks irrespective of whether the relations are in business, politics or everyday life. Because of the economic rise of China since the 1980s and its growing importance in the international economy through joint-ventures and other forms of relations between ethnic Chinese and non-Chinese individuals and companies, the interest shown by social and managerial researchers in guanxi has grown proportionally and a large literature has been generated which continues to grow.

Through the EBSCO host I conducted an on-line search of all peer-review journals for the period from January 1999 to December 2009 in which guanxi appeared as a key term in published articles. The EBSCO host is the premium international research database service and includes a broad range of full text and bibliographic databases designed for research. My search was limited to 'scholarly (peer-reviewed) journals' with 'publication type' limited to 'academic journal'. While the all-language search resulted in 215 items the English-language sources provided a total number of 214 items. The literature mentioned here is almost wholly concerned to understand Chinese or Chinese-foreign business or management relationships in which guanxi plays a significant role.

There are three possible forms of relations between the concept of guanxi and the theory it is applied to. The first is that guanxi is subject to explanation through application of a Western or mainstream theory in so far as the concept refers to a particular subject matter which is dealt with by the theory in question. In this sense the concept affects the structure of the theory and its explanations in the most limited sense, and only in so far as it is necessary to specify a subject matter in the same way that a theory of economic inequality might be unaffected by whether the inequality it treats is measured in US dollars, British pounds, French francs or Chinese renminbi. The second possibility is that a concept is seen as rounding out or providing a new perspective on the theory applied to it. In this sense the concept of guanxi may be said to contribute to the development of the theory that incorporates it or at least key aspects of the relations or factors it refers to. In this manner Lin (2001), in drawing on an analysis of guanxi, made a contribution to the theory of social capital by distinguishing between social capital that occurs at the interpersonal level and social capital that arises at the societal level (Chu, 2010).

There is a third possibility, namely that aspects of guanxi could be applied to existing theoretical concerns in a way that transforms them. Discussion of trust in empirical social science tends to focus on limited iterations or short-term contacts. A characteristic of guanxi, however, is enduring long-term relations. In a discussion of pricing differences in manufacture-wholesaler relations in the United States Carlton (1989) shows that the duration and stability of the association is crucial in providing a more favourable price for the wholesaler. The factual situation Carlton describes is more or less equivalent to a key aspect of guanxi relationships, and a theory of wholesale pricing could be strengthened by explicitly developing the relevant content of the concept of guanxi which is absent in current discussion of this theme. In this instance the Chinese concept guanxi may be incorporated into the interior of the theory and thereby generate a transformation of existing theory in a way that 
may not otherwise occur. This latter instance can be regarded as knowledge flow from the periphery to the core. The three possibilities outlined here are summarised in Table 1.

\begin{tabular}{|c|c|c|c|}
\hline $\begin{array}{c}\text { DIRECTION OF } \\
\text { KNOWLEDGE } \\
\text { FLOW } \\
{[\mathrm{M}=\text { Metropole }]} \\
{[\mathbf{P}=\text { Periphery }]}\end{array}$ & $\begin{array}{c}\text { CONCEPT- } \\
\text { THEORY } \\
\text { RELATION }\end{array}$ & $\begin{array}{c}\text { PLACE OF } \\
\text { GUANXI IN THE } \\
\text { THEORY }\end{array}$ & $\begin{array}{c}\text { SCOPE OF } \\
\text { THE } \\
\text { CONCEPT } \\
\text { OF } \\
\text { GUANXI }\end{array}$ \\
\hline $\mathrm{M} \rightarrow \mathrm{P}$ & External & $\begin{array}{c}\text { Object of } \\
\text { explanation } \\
\text { (explanandum) }\end{array}$ & $\begin{array}{c}\text { Local } \\
\text { relevance } \\
\text { only } \\
\end{array}$ \\
\hline $\mathrm{M} \leftrightarrow \mathrm{P}$ & $\begin{array}{l}\text { Internal (non- } \\
\text { directing) }\end{array}$ & $\begin{array}{c}\text { Secondary } \\
\text { explanatory concept } \\
\text { (explanans) }\end{array}$ & $\begin{array}{c}\text { Partial } \\
\text { general } \\
\text { relevance }\end{array}$ \\
\hline $\mathrm{M} \leftarrow \mathrm{P}$ & Internal (directing) & $\begin{array}{l}\text { Primary explanatory } \\
\text { concept (explanans) }\end{array}$ & $\begin{array}{l}\text { Universal } \\
\text { relevance }\end{array}$ \\
\hline
\end{tabular}

Table 1: Knowledge Flow and Theory Development

\section{Discussion of Guanxi in Academic Journals}

As noted above, an EBSCO search of peer-review journals for the period from January1999 to December 2009 in which guanxi appeared as a key term yielded 214 Englishlanguage items while the all-language search yielded 215 items. This suggests that English is the major language for international social science research and enjoys the predominant role in conveying and disseminating concepts, theories and ideas in globalized knowledge processes. I say 'suggests' because the EBSCO host databases are not neutral instruments. EBSCO has offices in the UK, Europe, Australia, Japan and India, with its headquarters in the United States. EBSCO is not only an agent in what James and McQueen-Thomson (2002) call the 'commodification of knowledge' but also the very construction of knowledge itself, including through language filters. Language as a tool of communication is a significant factor associated with uneven knowledge flows. Crystal (1997: 53) succinctly summarizes the two factors which lead to the world status of English: 'the expansion of British colonial power, which peaked towards the end of the nineteenth century, and the emergence of the United States as the leading economic power of the twentieth century'. Crystal goes on to stress that it is 'the latter factor which continues to explain the world position of the English language today'. Three-quarters of the world's mail is in English, about 80 percent of the world's electronically stored information is currently in English (Crystal, 1997: 105). Data compiled by the Index Translationum show that 55 percent of all book translation is from English, compared with only 6.5 percent of translations into English (UNESCO, 2009: 14).

English has become a global language, and a major language for research and crossnational research organizations (Altbach, 2004: 10). In any given country the majority of academic journals with an international readership are published in English. It is particularly interesting that even in a language-sensitive subject such as linguistics nearly 90 percent of the 1,500 papers listed in the journal Linguistics Abstracts in 1995 were in English (Crystal, 1997: 85, 102). Research students in non-English speaking European countries are highly likely to submit theses in English to their university in Berlin, Geneva, Stockholm, and so on. As Marginson (2008: 303) notes, the advent of 'a single mainstream system of Englishlanguage publication of research knowledge' has the significant effect of 'marginalis[ing nonEnglish] work rather than absorb[ing] it'. The dominance of English in research supports the other institutional and economic bases of the dominant position of Western theories and 
concepts. As a result universities in the South or periphery are increasingly led to adopt English as a medium of instruction.

Articles concerned with the concept of guanxi identified in the EBSCO search are overwhelmingly published in American and West European journals. The journals in which more than four articles about guanxi appeared in the period under review include: Journal of Business Ethics, International Journal of Human Resource Management, Journal of International Business Studies, International Business Review, Journal of Business Research and Journal of World Business. The frequency with which guanxi-relevant articles appeared in these journals is summarised in Table 2.

\begin{tabular}{|c|c|}
\hline JOURNAL & $\begin{array}{c}\text { NUMBER OF GUANXI-RELEVANT } \\
\text { ARTICLES }\end{array}$ \\
\hline Journal of Business Ethics & 25 \\
\hline $\begin{array}{c}\text { International Journal of Human Resource } \\
\text { Management }\end{array}$ & 11 \\
\hline Journal of International Business Studies & 8 \\
\hline International Business Review & 4 \\
\hline Journal of Business Research & 4 \\
\hline Journal of World Business & 4 \\
\hline
\end{tabular}

Table 2: Frequency of Guanxi-Relevant Articles in Premium Business and Management Journals, 1999-2009

All these journals are located in the metropole. The Journal of Business Ethics is published by Springer Science and Business Media. The International Journal of Human Resource Management is published by the Routledge, Taylor and Francis Group. The Journal of International Business Studies is published by Palgrave Macmillan. The International Business Review, Journal of Business Research and Journal of World Business are all published by Elsevier. English language journals published by major American, British or Western European organisations are typically bench-mark sites of theory and method in academic practices (Altbach, 2004: 8; Boden and Epstein, 2006: 229). Academic career trajectories, in terms of job opportunities, promotion and recognition, are determined by the rates of publication and possibly more importantly the ranking of refereed journals in which such publications appear. In order to publish in the prestigious journals it is not surprising, in light of the pattern of corporate domination of peer-reviewed journals reported in the above, that scholars find that they are led to 'address issues that are primarily of interest to the Western [academic] public' (Hountondji, 2002: 33). They therefore 'write in forms familiar to metropolitan editors: to use metropolitan concepts, address metropolitan literatures, and offer credible interventions in metropolitan debates' (Connell, 2007: 83). The fact that peer review of academic journal articles may include the participation of persons outside the American and British location of the journal's head office does not modify the structure of intellectual hegemony which dominates academic publishing.

As well as identifying journals and their location I also identified the institutional affiliation of their editors. The majority of the editors of the bulk of the search-identified journals hold academic positions at American, Canadian and Western European universities, as summarized in Table 3. It is through publications in internationally influential journals in English that the concept of guanxi receives attention in mainstream research and gains its importance. 


\begin{tabular}{|c|c|c|c|c|c|c|}
\hline JOURNAL & \multicolumn{6}{|c|}{ INSTITUTIONAL LOCATION OF EDITORS } \\
\hline & USA & Canada & UK & Europe & Australia & Asia \\
\hline $\begin{array}{l}\text { Journal of } \\
\text { Business } \\
\text { Ethics }\end{array}$ & 4 & 7 & 3 & $\begin{array}{l}3 \text { (Netherlands } \\
1 \text { and Spain 2) }\end{array}$ & $\begin{array}{l}1 \\
\text { (Australia) }\end{array}$ & \\
\hline $\begin{array}{l}\text { International } \\
\text { Journal of } \\
\text { Human } \\
\text { Resource } \\
\text { Management }\end{array}$ & & & 1 & & & \\
\hline $\begin{array}{l}\text { Journal of } \\
\text { International } \\
\text { Business } \\
\text { Studies }\end{array}$ & 7 & 1 & & $\begin{array}{l}3 \text { (Denmark } 1 \\
\text { and France 2) }\end{array}$ & & $\begin{array}{l}1 \\
\text { (Singapore) }\end{array}$ \\
\hline $\begin{array}{l}\text { International } \\
\text { Business } \\
\text { Review }\end{array}$ & & & 2 & $\begin{array}{l}2 \text { (Belgium } 1 \\
\text { and Norway } 1)\end{array}$ & & \\
\hline $\begin{array}{l}\text { Journal of } \\
\text { Business } \\
\text { Research } \\
\end{array}$ & 4 & 1 & 1 & & & 1 (Taiwan) \\
\hline $\begin{array}{l}\text { Journal of } \\
\text { World } \\
\text { Business } \\
\end{array}$ & 6 & & 1 & $\begin{array}{l}1 \\
\text { (Netherlands ) }\end{array}$ & $\begin{array}{l}1 \\
\text { (Australia) }\end{array}$ & $\begin{array}{l}1 \text { (Hong } \\
\text { Kong ) }\end{array}$ \\
\hline
\end{tabular}

Table 3: Frequency of Journal Editors by National Base of Institutional Membership

Among the 214 articles identified in the EBSCO search only 26 were published in journals which have the words 'Asia' or 'Asian' in their titles. The majority of these appear in 4 journals. During the period 1999 - 2009 seven articles in the sample appeared in Asia Pacific Journal of Management, 4 in the Asia Pacific Business Review, and 3 each in Journal of Asian Business and Asian Case Research Journal. The Journal of Asian Business is in fact an American journal and not surprisingly its editors are all based in American universities. The publisher of Asia Pacific Business Review is Routledge, Taylor and Francis Group and all of its editors are scholars who work in UK universities. The most international of these journals is the Asia Pacific Journal of Management in so far as 10 of its editors are academics working in American, Canadian and British universities. The remaining 11 editors of this journal have institutional affiliation in Asian universities though 8 have $\mathrm{PhDs}$ from universities in the USA, and one each from Canadian, Australian and Japanese universities.

Of those English-language journals which are wholly operated by an Asian university or organizations it is nevertheless typical that their editors have $\mathrm{PhDs}$ from universities in the metropole. The Journal of Asian Business is edited by two academics who are affiliated with American universities and the Asia Pacific Business Review by four who work at British universities. The Asia Pacific Journal of Management has an editorial list comprising twentyone scholars, six of whom are affiliated with American universities, two with Canadian universities, one with a British and one with an Australian university. Among the remaining eleven editors who have affiliation with Asian universities, eight earned their $\mathrm{PhD}$ in the United States, one in Canada, one in Australia and one in Japan. The Asian Case Research Journal, which is hosted by the National University of Singapore, is edited by academics who 
undertook their $\mathrm{PhD}$ studies either in the United States or Canada. More than half of the academics on the journal's editorial advisory board are employed by American universities. The present structure of academic journal publishing is a major contributing factor in the tendency for the diffusion of Western theories and concepts to flow to the rest of the world. When academics discuss issues relating to the periphery of the globalized world they tend to write in a way that Western editors are familiar with and draw upon theories and concepts generated in the metropole.

Turning now to the articles themselves identified in the EBSCO Search, we can begin with a brief comment on the methods they adopt. One-third of the 214 articles reviewed adopted survey methods, with a survey questionnaire sent to companies or managers. The next most popular method used was interviews, which were used in 15 percent of the 214 articles. Other methods adopted include literature review, content analysis, and case studies. These are all standard techniques of research developed in mainstream social science. The findings confirm the concern expressed by Connell (2007: 218) that 'ideas, terminology and research technologies get exported from the metropole to the periphery'. One of the consequences is that methods developed in the metropole may fail to adequately accommodate local characteristics to which they are applied. Jia (2001: 97), in his social constructionist theory of face and Chinese character, finds that methodological assumptions of institutional dynamism and social interaction fail to appreciate the hierarchical nature of Chinese social relations or the power of norms of social harmony in them.

The 214 articles under consideration here predominantly discuss issues related to guanxi in mainland China. Only 18 percent of the articles treat issues related to guanxi in other regions including Taiwan, Hong Kong, Singapore, Malaysia and Indonesia. The tone and sometimes stated purpose of the majority of these articles indicate that they are written for a readership interested in the issues and problems of foreign or Western business ventures in the Chinese economy, and also for organizations which intend to enter Chinese markets or which have investment or joint venture projects in China. The anticipated readership is Western, predominantly academic but with a clear applied focus.

We shall now turn to the treatment of the concept of guanxi in the 214 articles identified in the EBSCO search. The articles predominantly discuss the concept in terms of operational business issues pertinent to Chinese-Western interactions, in which guanxi has drawn increasing attention from researchers and practitioners alike. Associated with this orientation, according to Chen and Chen (2004: 305), guanxi 'has recently gained its status as a legitimate socio-cultural construct in Western mainstream literatures of cultural anthropology, sociology, social psychology, political science, and business and management'. Indeed, the intellectual framework in which guanxi is discussed in the 214 articles is supported by a cultural anthropology literature which insists on the unique Chinese nature of guanxi (Yang, 1994; Yan, 1996). This view has been challenged in an important article by Guthrie (1998), who argues that guanxi can be viewed as 'an institutionally defined system i.e. a system that depends on the institutional structure of society rather than on culture - that is changing in stride with the institutional changes of the reform era' (Guthrie, 1998: 255).

Approximately 95 percent of the articles in my sample use the Chinese concept of guanxi simply to refer to an empirical relationship or type of relationship that can be identified and possibly explained in terms of existing mainstream theory. The concept, then, identifies a particular subject matter that has no implication in the articles under review for concept refinement or theory development. For instance, guanxi is indicated as a type of relationship or interaction which is located in relations between supplier and buyer, supplier and retailer, supervisor and subordinate, business establishment and development, new product development, business transactions, and so on. In this sense the concept has minimal presence in the structure of the theory used by researchers and its explanations, except in so 
far as it provides a specification of a subject matter which it does in a matter-of-fact way and without theoretical elaboration: guanxi is there to be seen and requires no theoretical apparatus for its identification.

While this literature engages with guanxi as an object of inquiry and a phenomenon to be explained in various ways, a large proportion of the discussion of guanxi therefore generates no more theoretically significant appreciation of the nature of guanxi as a type of relationship in general than the dummy theory of inequality mentioned earlier distinguishes between currencies. This constitutes the first type of the concept-theory relation in which the explanatory form of the theories in the studies reported is unaffected by their use of the concept of guanxi. An overwhelming majority of researchers thus overlook the possibility that guanxi might refer to aspects of relationships upon which thematic reflection could lead to modification or redirection in existing theories of economic, business or social relations in general that are not currently developed in existing social science or management approaches.

While the vast majority of the articles in my sample treat the concept of guanxi as external to the theory which refers to it, because it exists only as an object of explanation, two other possibilities are identified in Table 1. It is possible that a Chinese concept might operate in an explanatory role as a result of an appreciation of its relevance beyond the instance of its immediate appearance. In this case the original theoretical apprehension of the concept leads to some change in the original theory. On this basis it can be said that knowledge flow is no longer uni-directional. This possibility can have a weak and a strong form, as indicated respectively in the second and third rows of Table 1. Examples of the weak form were found in less than five percent of the articles in the EBSCO sample.

Geddie, DeFranco and Geddie (2002), in their paper 'From Guanxi to Customer Relationship Marketing', discuss similarities between the Chinese construct of guanxi and the Western construct of 'customer relationship marketing'. They show that guanxi relations incorporate four distinct constructs, namely trust, bonding, reciprocity and empathy. They argue, on the basis of this distinction, that the four constructs of guanxi are capable of enhancing 'a better understanding of the importance of some of the basic concepts of CRM [customer relationship marketing] that are too often ignored' (Geddie, DeFranco and Geddie, 2002: 21). Customer relationship marketing is concerned with the provision of personal attention and 'relationship building' as a method of increasing customer loyalty as a marketing technique. The analysis of guanxi and the resulting distinction of its elements by Geddie, DeFranco and Geddie allows them to re-specify the nature of customer relationship marketing through an articulation of their constructs of guanxi in the conception and execution of this form of marketing. While this is not sophisticated theorizing Geddie, DeFranco and Geddie's argument is an instance of the incorporation of a Chinese concept in transformation of an existing theory concerning marketing.

Another instance of this form of knowledge flow is in a paper by Standifird and Marshall (2000), 'The Transaction Cost Advantage of Guanxi-Based Business Practices'. They argue that guanxi should be seen as 'about the cultivation of long-term personal relationships' and in that sense it 'does not appear to be unique [to Chinese culture], and in fact it exists in some extent in every human society' (Standifird and Marshall, 2000: 22). All economies, they argue, entail transaction costs, costs incurred in 'running the system' which 'include such ex ante costs as drafting and negotiating contracts and such ex post costs as monitoring and enforcing agreements' (Standifird and Marshall, 2000: 25). The authors note that a limitation of transaction cost analysis is in its 'fail[ure] to recognize the importance of institutional environments' (Standifird and Marshall, 2000: 28-9). They go on to note that 'the guanxi network ... [constitutes] an independent structural alternative [to contract law]' (Standifird and Marshall, 2000: 29) and therefore provides a valid and viable qualification to existing transaction cost theory. 
Standifird and Marshall (2000) show that guanxi-based business practices offer certain transaction cost advantages over existing structural alternatives identified in the theory. As well as showing that guanxi-based exchange deals with governance problems associated with bounded rationality and opportunism, Standifird and Marshall (2000: 38) demonstrate the relevance of the Chinese concept of guanxi to non-Chinese cultures: 'guanxi-based business practices can be explained regardless of cultural embeddedness effects'. While in effect agreeing with Guthrie (1998: 255), that guanxi is best seen as 'an institutionally defined system - i.e. a system that depends on the institutional structure of society rather than on culture', Standifird and Marshall (2000: 40) argue that precisely because of this fact 'guanxibased business practices will not diminish in importance to the extent previously predicted' because of the transaction cost advantages they offer. Particularly relevant for the present discussion is the fact that through their focus on guanxi Standifird and Marshall modify transaction cost theory itself.

The discussion of the findings of Geddie, DeFranco and Geddie and also those of Standifird and Marshall indicates the potential contribution of the concept of guanxi to the social sciences through theoretical modification or transformation. The nuanced properties and characteristics of this concept can be utilized to augment and refine social theory. While there is a significant apprehension of this Chinese concept in research reported in Englishlanguage journals the theoretical discussion in the majority of these papers remains unaffected by the heuristic possibilities of the concept. The review of 214 refereed journal articles, in which guanxi appears as a key term, confirms the continuance and persistence of asymmetrical knowledge flows in social and management science.

\section{Conclusion}

This case study of a Chinese concept in social and management science journals provides an empirical analysis of knowledge flows in a contemporary situation. This review of 214 refereed journal articles published during the period 1999 to 2009 has shown that guanxi as a non-English-language concept gains recognition in social science, business and management research through English-language journals. These journals are predominantly organs of North American and British or European universities or associations. Even those English-language journals published from Asian universities or associations, such as the Asian Case Research Journal, are likely to be managed by people who have North American, British or West European PhDs. The discussion of this Chinese concept in the papers reviewed here is primarily concerned with issues related to China, extending to Chinese business culture in Southeast and East Asia. A majority of the papers provide insight and advice to Western businesses conducting or intending to conduct business in China. It was shown that approximately 95 percent of the papers reviewed treated guanxi as a particular subject to be explained by standard Western theories which remained unaffected by their application to this material. The overwhelmingly common practice has been to treat guanxi as an exotic phenomenon and almost exclusively as an object of study, rather than a theoretically-significant concept with a capacity to contribute to theory development. A small number of the remaining papers did indicate theoretical modification as a result of integrating the concept of guanxi, no matter how slightly, into their explanations.

The treatment of a foreign concept such as guanxi provides a measure of the nature and degree of knowledge flows under globalization. This paper sheds light on the issue concerning knowledge flows and these findings confirm the dominance of North American, British and Western European researchers in the production and circulation of concepts, theories and methodologies in a knowledge flow which is directed from the metropole to the periphery. This dominance persists even when the subject matter is exogenous and sufficiently theory-laden as to produce alternative knowledge. 
Knowledge flows and their organisational and cultural apparatuses are to a great degree structured in a manner that supports Hannerz's argument of asymmetries rather than the de-centredness proposed by Appadurai and also Lash and Urry; the patterns within such structures have tended to maintain the inequalities associated with the idea of Western dominance. While there is no simple direct or one-way flow of knowledge under globalization it is shown that economic resources and capacities underlie the creation, collection and transmission of knowledge. Political frameworks, purposes and interests and academic institutions and practices tend to influence the shape, forms and directions in which knowledge flows. The contemporary situation of asymmetrical knowledge flows continues to support the predominance of knowledge forms that originate in the centres of global economic and political power.

This case study indicates that while globalizing processes have progressively and increasingly integrated various currents and flows of knowledge - in both intellectual content and conveying media - the direction of these flows, is more or less consistent with the attraction exerted by the concentrations of economic and political power that can be located in the global knowledge networks. Knowledge can always be assessed and judged in its own terms, as being correct or proven or useful in making sense of the things it addresses. But the economic resources and capacities that underlie the creation, collection and transmission of knowledge, and the political frameworks, purposes and interests that shape, direct and interpret such knowledge are central concerns in understanding the configuration of knowledge flows under all conditions, and the conditions of globalization in particular. The neglect of relevance of foreign concepts such as guanxi for understanding aspects of social and economic relationships in general and their significance for theory development reveals the continuance of asymmetrical knowledge flows under globalization.

The ways in which guanxi is treated in the literature reported in this study overlook broader implications of the concept and therefore miss opportunities to expand the competence of existing theories. The study of Geddie, DeFranco and Geddie discussed above shows that identification of theory-relevant elements of guanxi potentially encourages a more nuanced understanding of concepts of customer relationship marketing and therefore possibilities of augmenting existing marketing theory. Standifird and Marshall's research reveals that recognition of properties of guanxi relations indicates certain transaction-cost advantages and opportunities for enhancing existing theory. In addition, aspects of guanxi have relevance for understanding general aspects of social-capital type relations and therefore have significance in the refinement of social capital theory. Examination of guanxi may indeed highlight aspects of social relationships which hitherto have not received the attention they deserve in amplifying not only social capital theory but also pricing theory (Qi 2012). While acknowledging that the types of particularistic ties and the intensity of their application may vary between societies, guanxi as a Chinese form of social relations has elements that exist in all societies. This paper draws attention to the way in which concepts from nonWestern cultures have been and can be treated by social researchers. Other concepts from non-Western cultures might also be integrated into global social theory and lead to theoretical enrichment, augmentation and refinement.

\section{References:}

Altbach P G (2004) Globalisation and the University. Tertiary Education and Management 10(1): 3-25.

Appadurai A (1990) Disjuncture and Difference in the Global Cultural Economy. Theory, Culture and Society 7(2): 295-310. 
Bauman Z (1998) On Globalization: Or Globalization for Some, Localization for Others. Thesis Eleven 54(1): 37-49.

Beerkens E (2010) Global Models for the National Research University. Globalization, Societies and Education 8(3): 369-391.

Boden R and Epstein D (2006) Managing the Research Imagination? Globalisation, Societies and Education 4(2): 223-236.

Bourdieu P (1999) The Social Conditions of the International Circulation of Ideas. In: R Shusterman (ed) Bourdieu: A Critical Reader. Oxford: Blackwell Publishers, 220-228.

Carlton D W (1989) The Theory and Facts of How Markets Clear. In: R Schmalensee and R D Willig (eds) Handbook of Industrial Organization, volume 1. New York: Elsevier, 909-946.

Castells M (1996) The Rise of the Network Society. Oxford: Blackwell.

Chen X and Chen C C (2004) On the Intricacies of the Chinese Guanxi: A Process Model of Guanxi Development. Asia Pacific Journal of Management 21: 305-324.

Chu Y (2010) Engaging the Global Knowledge Community. Presented in the International Conference on the Globalization of Korean Political Science, 30 April 2010.

Connell R (2007) Southern Theory: The Global Dynamics of Knowledge in Social Science. Sydney: Allen and Unwin.

Crossman P and Devisch R (2002) Endogenous Knowledge in Anthropological Perspective. In: C A O Hoppers (ed) Indigenous Knowledge and the Integration of Knowledge Systems. Claremont: New Africa Books, 96-125.

Crystal D (1997) English as a Global Language. Cambridge: Cambridge University Press.

Dai K (1993) The Vicissitudes of Sociology in China. International Sociology 8(1): 91-99.

Delanty G (1999) Social Theory in a Changing World. Cambridge: Polity Press.

Fleck L (1981) Genesis and Development of a Scientific Fact. Chicago: University of Chicago Press.

Geddie M W, DeFranco A L and Geddie M F (2002) From Guanxi to Customer Relationship Marketing. Journal of Travel and Tourism Marketing 13(3): 19-33.

Guthrie D (1998) The Declining Significance of Guanxi in China's Economic Transition. The China Quarterly 154: 254-282.

Hannerz U (1997) Flows, Boundaries and Hybrids. In: A Rogers (ed) Transnational Communities Programme, Working Paper Series. Institute of Social and Cultural Anthropology, University of Oxford.

http://www.transcomm.ox.ac.uk/working\%20papers/hannerz.pdf (accessed 17 October 2010).

Hannerz U (2008) The Global Ecumene. In: F J. Lechner and J Boli Malden (eds) The Globalization Reader. Blackwell Publishing, 105-116.

Holton R J (2005) Making Globalization. London: Palgrave MacMillan.

Hountondji P J (2002) Knowledge Appropriation in a Post-colonial Context. In: C A O Hoppers (ed) Indigenous Knowledge and the Integration of Knowledge Systems. New Africa Books, 23-38.

James P and McQueen-Thomson D (2002). 'Abstracting Knowledge Formation'. In: S Cooper, J Hinkson and G Sharp (eds) Scholars and Entrepreneurs: The Universities in Crisis. Melbourne: Arena Publications Association, 183-205.

Jia W (2001) The Remaking of the Chinese Character and Identity in the $21^{\text {st }}$ Century: The Chinese Face Practices. Westport: Ablex.

Kuhn T S (1970) The Structure of Scientific Revolutions. $2^{\text {nd }}$ edition. Chicago: University of Chicago Press.

Lash S and Urry J (1994) Economies of Signs and Space. London: Sage. 
Lin N (2001) Social Capital: A Theory of Social Structure and Action. New York: Cambridge University Press.

Lingard B (2006) Globalisation, the Research Imagination and Deparochialising the Study of Education. Globalisations, Societies and Education 4(2): 287-302.

McMahon M E (1992) Higher Education in a World Market. Higher Education 24(4): $465-$ 482.

Marginson S (2008) Global Field and Global Imagining. British Journal of Sociology of Education 29(3): 303-315.

Miike Y (2006) Non-Western Theory in Western Research?. Review of Communication 6 (1): 4-31.

Moran A and Keane M (2010) Introduction: The Global Flow of Creative Ideas. In: A Moran and M Keane (eds) Cultural Adaptation. London: Routledge, 1-8.

Nordtveit B H (2010) Toward Post-globalization? Globalization, Societies and Education 8(3): 321-337.

Qi X (2013) Guanxi, Social Capital and Beyond: Toward a Globalized Social Science (forthcoming).

Standifird S S and Marshall R S (2000) The Transaction Cost Advantage of Guanxi-Based Business Practices. Journal of World Business 35(1): 21-42.

Turner B S and Khondker H H (2010) Globalization: East and West. Los Angeles: Sage.

UNESCO (2009) World Report: Investing in Cultural Diversity and Intercultural Dialogue. Paris: UNESCO.

Wu, X (2009) Between Public and Professional: Chinese Sociology and the Construction of a Harmonious Society. ASA Footnotes 37(5).

http://www.asanet.org/footnotes/mayjun09/intl_0509.html (accessed 1 November 2011).

Yan Y (1996) The Flow of Gifts. Palo Alto: Stanford University Press.

Yang M M (1994) Gifts, Favours and Banquets. Ithaca: Cornell University Press. 